\title{
VERBORGEN SCHOONHEID UIT JAPAN \\ 'Outsider Art overflows, there are no limits' 1
}

In Nederland is nu voor het eerst Japanse outsiderkunst te zien, in de tentoonstelling 'Verborgen schoonheid uit Japan' in museum Het Dolhuys te Haarlem.

\section{Outsiderkunst}

Outsiderkunst, ook wel outsider art of art brut genoemd, is in de kunstwereld een relatief nieuw begrip. Toen de term in 1948 voor het eerst werd geïntroduceerd door Jean Dubuffet viel onder deze noemer zowel kunst van psychiatrische patiënten als die van kunstenaars die de conventionele 'hoog-lage' kunstwereld hebben afgewezen. De outsiderkunstenaars zijn niet in eerste instantie gericht op het tentoonstellen van hun werk noch op roem of erkenning voor hun werk. Ze zijn niet opgeleid tot kunstenaar en vaak is de outsiderkunstenaar autodidact. Hij werkt vanuit een zekere dwangmatigheid, voor zichzelf en niet voor anderen, zonder commerciële bijbedoelingen. Dubuffet noemde de outsiderkunstenaar een kunstenaar die uit het niets creëert; iemand die zich niet laat beïnvloeden door kunstenaars die hem voorafgingen of door eigentijdse kunstenaars. Dit laatste wordt tegenwoordig in twijfel getrokken. Men gaat ervan uit dat elke kunstenaar, ook de outsider, beïnvloed wordt door tekeningen, illustraties uit tijdschriften et cetera.

De outsiderkunstenaar is niet iemand die zich buiten de cultuur plaatst.

Dit zou onmogelijk zijn. (afb. 1)

Enerzijds valt outsiderkunst onder de noemer kunst, maar anderzijds is het werk van een outsiderkunstenaar een vreemde eend in de bijt. Het sluit niet echt aan bij welke traditie dan ook in de Westerse kunst of andere leidende kunstcultuur.

Om het werk van een professionele kunstenaar te begrijpen is het van belang te weten welke positie hij wil innemen ten opzichte van de gezaghebbende canon. Echter, om het werk van een spontane kunstenaar te begrijpen moet men eigenlijk zijn biografie, zijn dromen en zijn fascinaties kennen.

\section{Ontstaan tentoonstelling}

Museum Het Dolhuys, het museum voor de psychiatrie, biedt kunstenaars met een psychiatrische stoornis of een verstandelijke handicap de mogelijkheid naar buiten te treden en hun kunstwerken in contact te brengen met de buitenwereld. In de Japanse cultuur is het tot op heden niet geaccepteerd om van de norm af te wijken. Geestesziekte wordt als 'eng' beschouwd. Mensen met een psychiatrische stoornis worden daar vaak letterlijk binnengehouden. Hans Looijen, directeur van Het Dolhuys, bezocht in 2010 de tentoonstelling 'Art Brut Japonais' in de Halle Saint Pierre te Parijs waar sommige yan deze kunstenaars voor het eerst hun werk exposeerden. De tentoonstellingatroke access 


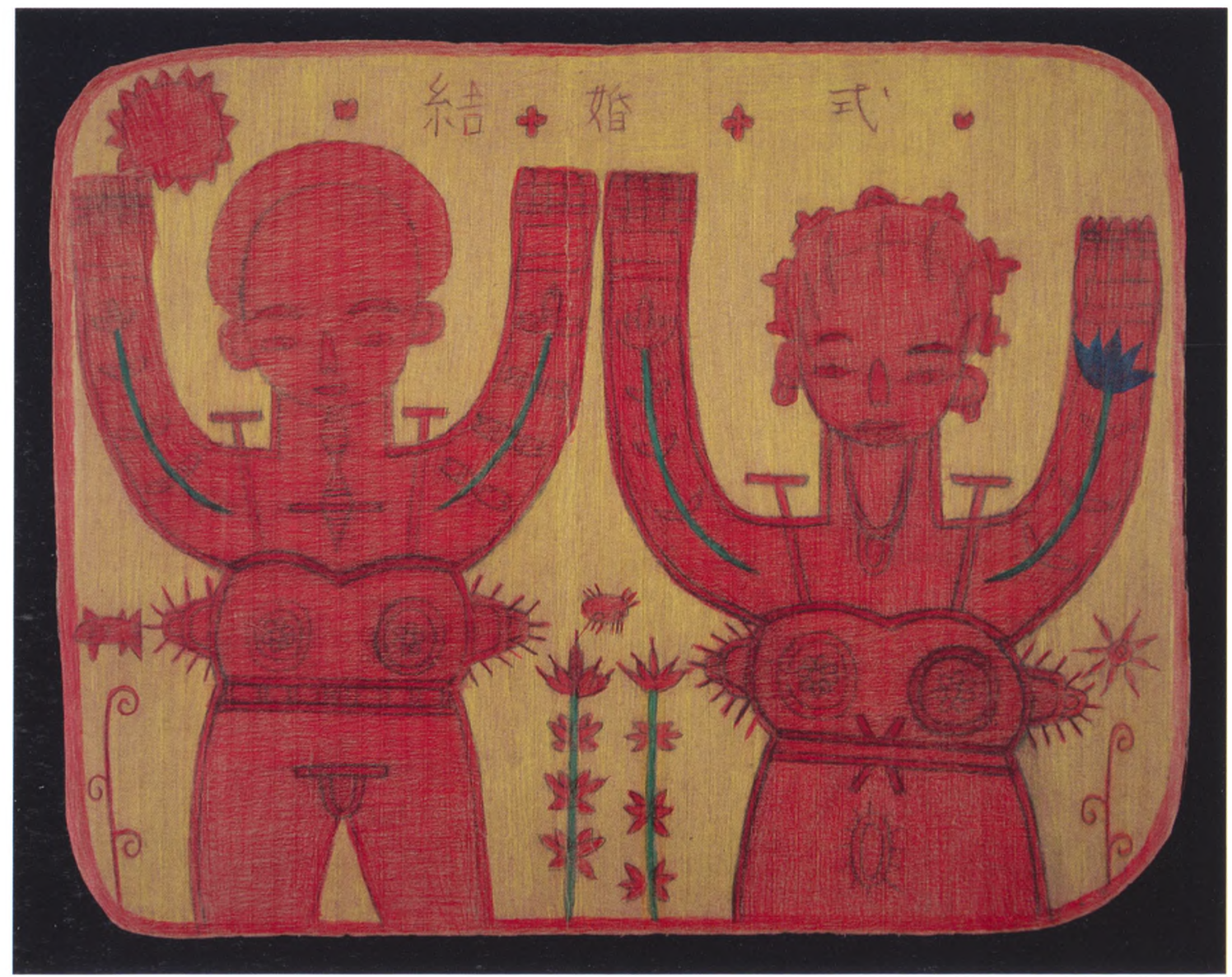

Afb. 2

Masao Obata, Untitled (wedding), penseel op karton, 34,6 × 44,4 cm., jaartal onbekend
120.000 bezoekers en was dankzij veel media-aandacht een groot succes. Omdat Looijen benieuwd was naar de persoonlijke verhalen van de makers, reisde hij naar Japan waar hij de outsiderkunstenaars opzocht. Hij selecteerde uiteindelijk de werken van 46 Japanse kunstenaars met een psychiatrische stoornis of een verstandelijke handicap. Ongeveer 25 van hen exposeren voor het eerst in Europa. Een unieke, taboedoorbrekende tentoonstelling.

De voorzitter van de Shiga Prefecture Social Welfare Institute, Kengo Kitaoka, had al langer als droom dat de werken van de patiënten van de Shiga Prefecture zouden worden tentoongesteld voor een breder publiek. ${ }^{2}$ In 2008 werd deze droom werkelijkheid toen in Lausanne, in Collection de l'Art Brut, de tentoonstelling 'Japon' werd georganiseerd. Twee jaar later volgde, zoals zojuist vermeld, 'Art Brut Japonais' in Parijs. Kengo Kitaoka hoopt dat de werken van de psychiatrische patiënten en verstandelijk gehandicapten ooit worden opgenomen binnen de Japanse cultuur, zoals ook de outsiderkunst in Europa een plek heeft gevonden o7:56:23AM binnen de moderne kunst. 


\section{Outsiderkunst in Japan}

De vraag rijst in hoeverre het uitmaakt waar outsiderkunst vandaan komt. Is er echt een aanzienlijk verschil tussen outsiderkunst uit bijvoorbeeld Europa, de Verenigde Staten en Japan? Of kent outsiderkunst een universele beeldtaal? Het gaat immers om mensen die buiten de gevestigde kunststromingen om, hun eigen wereld scheppen. Terwijl de Japanse beeldcultuur zozeer verschilt van die van Europa en de Verenigde Staten, laten de werken van Japanse outsiderkunstenaars dezelfde basispatronen en vormen zien als de westerse outsiderkunst.

Het is opvallend hoe jong de meeste Japanse outsiderkunstenaars zijn. In vroeger dagen waren de psychiatrisch patiënten opgesloten in inrichtingen en letterlijk gescheiden van het normale bestaan. Ze beschikten nauwelijks over pennen, papier, verf of andere materialen. Ze gebruikten wat voorhanden was. De huidige generatie outsiderkunstenaars gaat naar speciaal voor hen opgerichte ateliers waar ze rijkelijk voorzien worden van schrijfwaren, papier, verf, klei en garens. Ze maken bovendien veel meer deel uit van de gewone wereld: ze kijken televisie, gebruiken soms computers en gaan naar films.

\section{Taboedoorbrekende tentoonstelling}

En nu is er voor deze groep Japanse outsiderkunstenaars een kans om in Het Dolhuys hun werken te laten zien aan de rest van de wereld. De tentoonstelling 'Verborgen schoonheid uit Japan' is tot stand gekomen door samenwerking met de Asei Kai Organization en het Borderless Art Museum No-Ma in Japan.

\section{- Masao Obata}

Masao Obata (1943-2010) is een van de kunstenaars die in Het Dolhuys wordt geëxposeerd, maar van wie al eerder werk te zien was in Lausanne. Obata verzamelde sinds ongeveer 1992 kartonnen dozen in de keuken van het tehuis waar hij woonde. Hierop tekende hij vervolgens dag en nacht. Veel van zijn onderwerpen zijn bruiloften of families, die geen directe betrekkingen hebben op zijn eigen leven. De meeste personen die hij portretteert, hebben zorgvuldig getekende genitaliën, waardoor het erop lijkt dat Obata 'het geslacht' als een belangrijk element van het menselijk leven beschouwt ( $a f b$. 2). Alle tekeningen van zijn hand zijn gemaakt in een onderscheidende, zelf verzonnen stijl en niets is gebaseerd op observaties. Helaas zijn in de loop der tijd veel van zijn tekeningen weggegooid op momenten dat zijn kamer werd uitgeruimd, totdat zijn werk werd ontdekt door een lokale kunstenaar. Sindsdien wordt het overal tentoongesteld. Zijn werken worden nu beheerd door een non-profit organisatie.

\section{- Marie Suzuki}

In de tentoonstelling is onder meer werk van Marie Suzuki (1979) te zien. Gefascineerd door het menselijk lichaam, waarbij borsten en genitaliën domineren, maakt zij expressieve schilderijen. Kunst is een onmisbare uitlaatklep voor haar. Suzuki's ziekte openbaarde zich op de middelbare school. Ze behaalde haar diploma via een schriftelijke cursus terwijl ze ondertussen naar workshops ging. Tegenwoordig verdeelt ze haar tijd tussen een bedrijf en een lokale zorginstelling. Haar werk is gebaseerd op herinneringen uit haar jeugd, die zij lange tijd had onderdrukt. Zij tekent overwloedige 


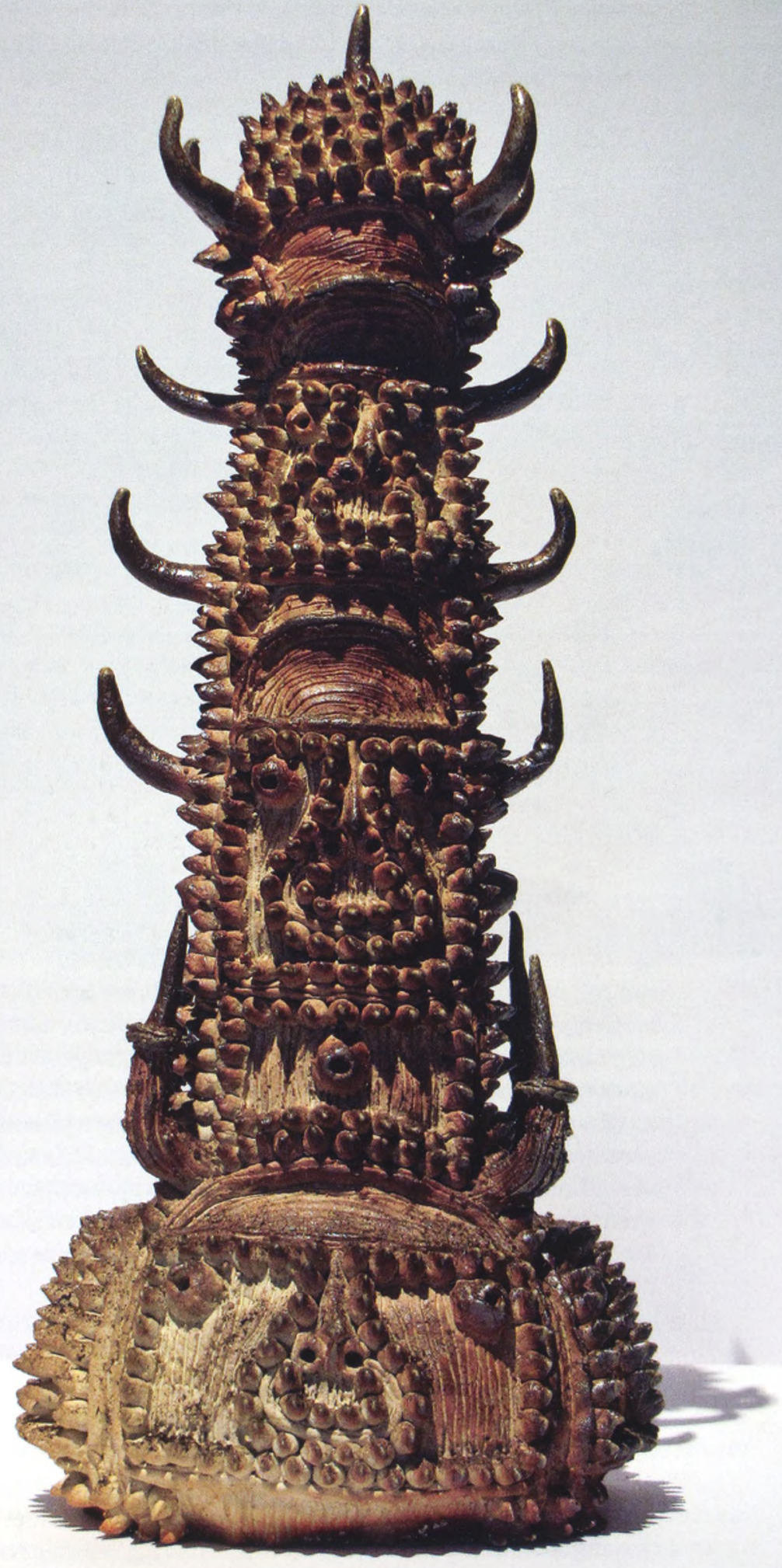


borsten en genitaliën, menselijke figuren die volwassenen noch kinderen zijn, en ontelbare scharen. In 2007 gaf zij voor het eerst uiting aan haar gevoelens op het doek. 'De bedenkelijkheid van het idee dat menselijk leven voortkomt

Afb. 3 Shinichi Sawada, Onbekend, klei, $44 \times$ $19 \times 19 \mathrm{~cm} ., 2010$

uit de baarmoeder, een afkeer van vrouwelijke en mannelijke genitaliën, en omgekeerd ook een obsessie met al deze dingen', zegt Suzuki. Tekenen helpt haar tot rust te komen en is een onmisbaar deel van haar dagelijkse leven geworden. ${ }^{3}$

Voor ze begon met het tekenen van deze werken tekende ze mensen en dieren op een bepaalde manier, geïllustreerd zoals men ze ziet op folders en filmposters.

\section{- Shinichi Sawada}

Ook bijzonder is het werk van Shinichi Sawada (1982). Op een zeer perfectionistische manier maakt hij aardewerken beelden die er uitzien als vriendelijke monsters. Sawada heeft een autistische stoornis en praat nauwelijks; hij communiceert via de kunst. ${ }^{4}$ Met zijn soepele, lange en ranke vingers maakt Sawada langzaam één voor één doornen vast aan zijn sculptuur (afb. 3). Soms lacht hij uit plezier en werkt vervolgens door in stilte. Zijn wonderbaarlijke sculpturen hebben al velen gefascineerd. Het is vooralsnog onduidelijk of hij een beeld in zijn hoofd namaakt of simpelweg doet wat zijn instinct hem ingeeft op het moment dat hij aan het werk is. Hij werkt kalm en ritmisch, zonder aarzelen, wat suggereert dat hij een visie heeft van hoe het voltooide werk er uit komt te zien. Zelfs grote beelden rondt hij af in vier of vijf dagen. Het bakken van de klei wordt gedaan door medewerkers van de instelling. Sawada werkt als broodbakker in een instelling voor mensen met een verstandelijke beperking en komt ongeveer twee keer per week naar de pottenbakkerij. Zijn kunst was onderdeel van de tentoonstelling 'Japon' in Lausanne en is opgenomen in Collection de l'Art Brut.

\section{- Masahiro Amasaki}

Er zijn ook Japanse kenmerken terug te vinden in de werken van de Japanse outsiderkunstenaars. Een van de eerste kunstwerken die het oog treft in de tentoonstelling is een groot schilderij van Masahiro Amasaki (afb. 4 en 5). Amasaki begon twintig jaar geleden met tekenen in de studio van een instelling voor mensen met geestelijke beperkingen. Hij houdt ervan om te plannen en heeft een soort jaaroverzicht gemaakt voor het tekenen van projecten, zoals 'Serie van Bloemen' en 'Serie van Japanse Dingen'.

Hij maakt voornamelijk olieverfschilderijen omdat hij gelooft dat 'schilderijen nu eenmaal met olieverf horen te worden geverfd'. Het duurt ongeveer een jaar om één schilderij af te ronden, omdat de studio maar eens per maand open is. Terwijl hij bezig is, verandert hij keer op keer de kleuren en vult elke vierkante centimeter van het papier met verschillende patronen. Het lijkt erop dat wat hij mooi vindt, is terug te vinden in deze gelaagde, zelfs opzichtige kleurencombinaties. Kalmpjes blijft hij schilderen terwijl hij zijn werk bekijkt met een ernstige blik in zijn ogen.

\section{- Yukiko Yamada}

Yamada (1943) begon rond haar zestigste met tekenen (afb. 6). Tot die tijd had ze nog nooit een potlood aangeraakt: ze kon immers niet schrijven. Yamada woonde bij haar moeder en hielp met het huishouden. Ze kwam nooit buiten behalve voor de boodschappen. Toen baar moeder ziek werd, 56:23AM verhuisde ze naar een groepswoning voor mensen met een verstandelitjkee access 


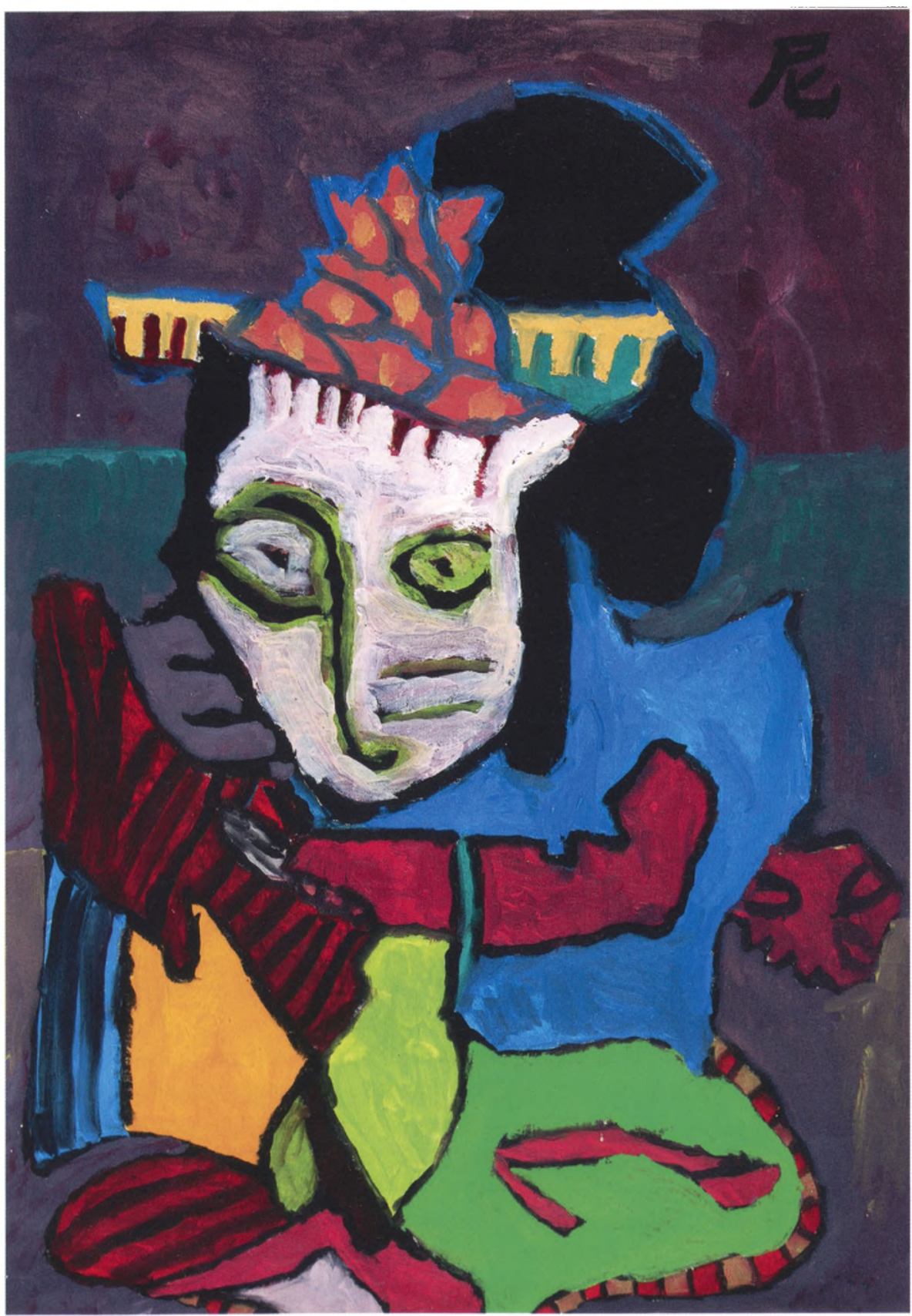

Afb. 5

Masahiro Amasaki,

Geisha, olieverf op

doek, 82 × 58 cm., 1996 
Afb. 6

Yukiko Yamada, She is nobody, potlood op papier, $45 \times 38 \mathrm{~cm}$., 2011

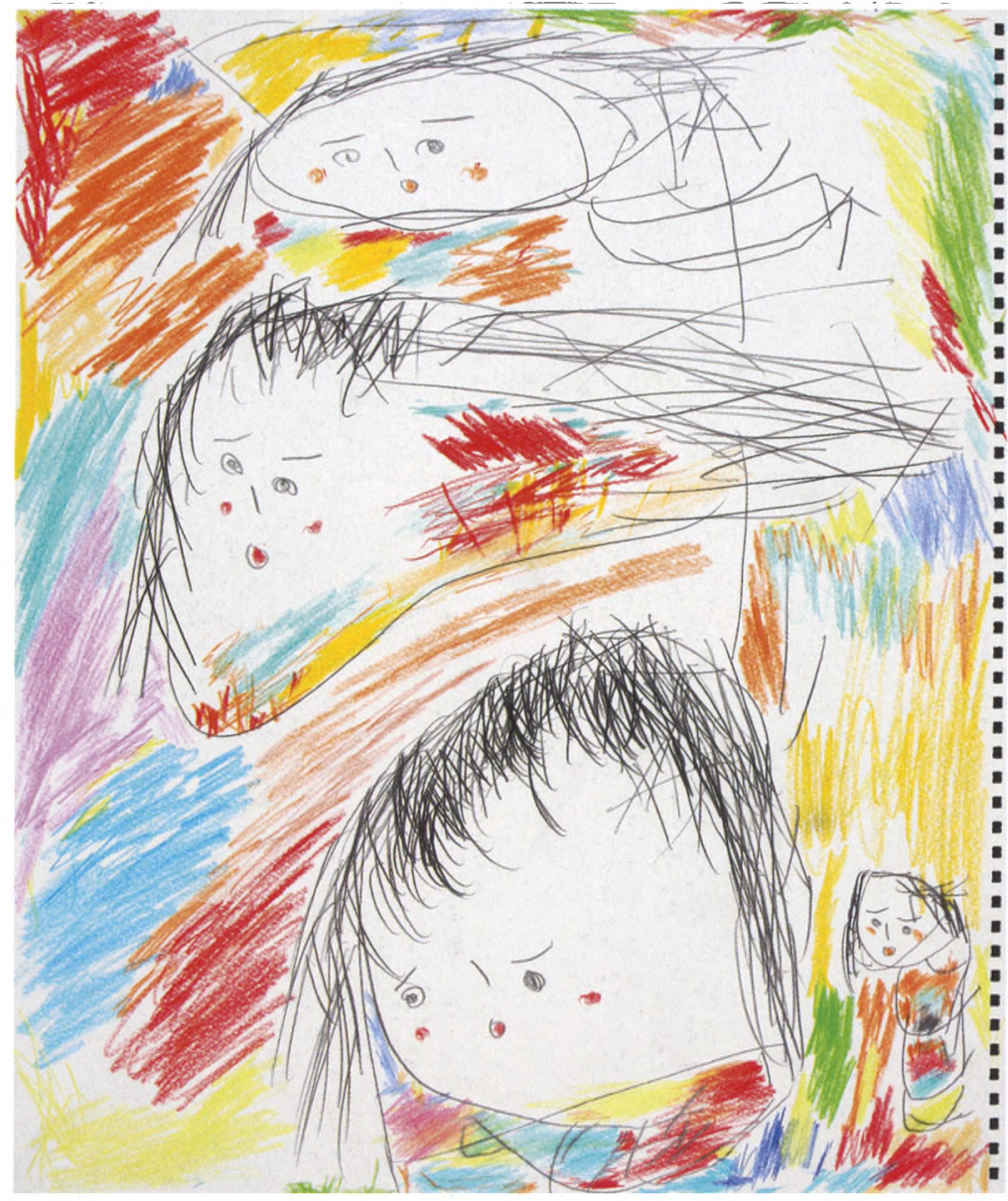

beperking. Ze maakte daar wenskaarten met tekeningen voor Nieuwjaar. Het was het begin van haar creatieve ontwikkeling. Yamada deed één keer per maand mee aan een workshop in de studio van de instelling. Als men vraagt naar de personen in haar tekeningen buigt ze altijd haar hoofd een beetje naar beneden en dan zegt ze 'dat is niemand'. Het is nu zeven jaar geleden sinds ze begonnen is met tekenen. Ze tekent nog steeds met veel enthousiasme, volgens haar familie, 'alsof ze probeert te compenseren voor het verleden'. Ze heeft haar unieke manier van uitdrukking gevonden. ${ }^{5}$

\section{Grotere zichtbaarheid}

Outsiderkunst is bijzonder expressief (afb. 7). Deze kunstenaars communiceren grotendeels via hun kunstwerken. Hun kunst functioneert als een onmisbare vorm van expressie. Op de tentoonstelling in Museum Het Dolhuys zijn bijna 1000 kunstwerken van 46 verschillende kunstenaars te zien. De kunstwerken worden gecombineerd met korte biografieën over de kunstenaars waardoor de verhalen van de kunstenaars nog duidelijker zichtbaar worden. Letterlijk en figuurlijk, want in Japan blijven mensen met een handicap vaak weggestopt achter gesloten deuren en in inrichtingen. Juist om die reden is deze tentoonstelling voor de kunstenaars van grote $e_{07: 56: 23 \mathrm{AM}}$ betekenis. 


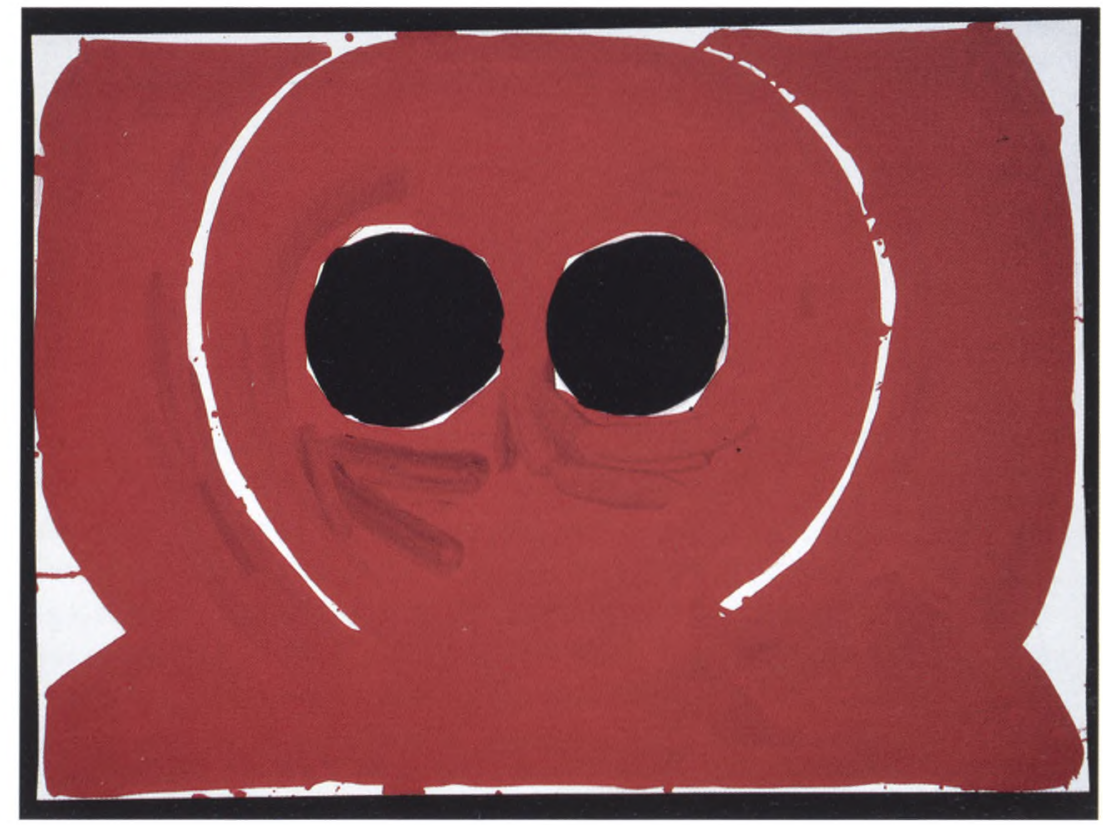

Tamar Herfs (1990) studeert Cultureel Erfgoed aan de Reinwardt Academie. Daarnaast loopt ze stage in museum Het Dolhuys, op de afdeling Marketing \& Communicatie.

\section{Te zien}

- Museum Het Dolhuys, Haarlem, 'Verborgen schoonheid uit Japan' 3 april - 2 september 2012

\section{Literatuur}

Amy Dempsey, Encyclopedie van de Moderne Kunst, Uitgeverij Waanders, Zwolle, 2010.

Y. Hata, T. Inoue, K. Kudo, M. Murai en R. Makihara. Outsider art from Japan, WBooks, Zwolle, 2012.

Michaja Langelaan, 'Japanse outsiderskunst in Het Dolhuys', Psy Magazine 5 (2012), p. 38.

http://www.museumdrguislain.be/index.php?option=com_content 8 rview=article\&id=16 68Itemid=968lang=nl (laatst bezocht 3 mei 2012).

http://nl.wikipedia.org/wiki/Jean_Dubuffet (laatst bezocht 9 mei 2012).

http://www.hetdolhuys.n//tentoonstellingen/verborgen-schoonheid-uit-japan (laatst bezocht 10 mei 2012).

\section{Noten}

1. Yoshiko Hata, art director Borderless Art Museum No-Ma

2. Y. Hata et al. 2012: 3.

3. Y. Hata et al. 2012: 106-7

4. Y. Hata et al. 2012: 103-5

5. Y. Hata et al. 2012: 26-8 